\title{
Etnografia do ambientalismo corporativo: notas para uma antropologia do estado de morte que marca o campo dos megaempreendimentos
}

Ethnography of corporate environmentalism: notes towards an anthropology of the state of death marking the field of mega-projects

\section{Rafael Gomes de Sousa da Costa}

Brasil. Universidade Federal de Minas Gerais. Doutorando em Antropologia pelo Programa de Pós-graduação em Antropologia. ID ORCID: http://orcid.org/00oo-0002-9122-5373. E-mail: rafaelgdscosta@gmail.com. Colaboração: Pesquisa bibliográfica, pesquisa empírica, análise de dados e redação.

\section{Maria Cecília Oliveira}

Alemanha. Institute for Advanced Sustainability Studies. Coordenadora do Grupo de Pesquisa (Re)configurações Democráticas das Transformações da Sustentabilidade, do Instituto de Estudos Avançados em Sustentabilidade do Instituto de Estudos Avançados em Sustentabilidade - IASS. ID ORCID: https://orcid.org/0000-0002-1661-4117. E-mail: mariacecilia.oliveira@iass-potsdam.de. Colaboração: Redação e revisão.

\section{Resumo}

Este texto é um ensaio etnográfico com base em situações vivenciadas pelo coautor Rafael da Costa enquanto trabalhava como analista ambiental no departamento de meio ambiente de uma corporação produtora de energia elétrica, entre 2010-2013, período em que integrava a equipe técnica responsável pela condução de programas de mitigação e compensação ambiental da Barragem Belo Monte, na Volta Grande do rio Xingu, Amazônia. Em uma abordagem antropológica, o ensaio busca descrever como os profissionais da expertise ambiental corporativa interpretam um mundo muito mais vasto do que aquele alcançado pelos jargões de sua atividade no cotidiano. Nosso objetivo é demonstrar como os modos 
mais íntimos de entendimento destes profissionais - os quais se estabelecem em contraste com os padrões técnicos requeridos da análise ambiental empresarial configuram fator produtivo das dimensões de destruição e morte que marcam o campo de um megaempreendimento.

Palavras-chave: Antropologia, Ambientalismo Corporativo, Belo Monte.

\section{Abstract}

This paper is an ethnographic essay based on the work experience of one of the authors (da Costa) inside the environmental department of an electric energy producer corporation, between 2010 and 2013, period during which he was part of the technical team responsible for conducting environmental measures of the Belo Monte Dam on the Xingu River, in the region known as Volta Grande, Amazon. Following an anthropological approach, the essay describes how the corporate environmental experts interpret a world vastly more complex than that reached by the jargon vocabulary of their professional activity in their daily lives. Our aim is to show how the most intimate understandings of these professionals - in contrast to the technical standards required by corporate environmentalism - configure a productive factor of the destructive and death dimensions that characterize the territories of a mega-project.

Keywords: Anthropology, Corporate Environmentalism, Belo Monte.

\section{AMBIENTALISMO CORPORATIVO}

O pesquisador Andrew Hoffman, em seu livro From Heresy to Dogma: An Institutional History of Corporate Environmentalism (2001), buscou apresentar a história do "ambientalismo corporativo" nos Estados Unidos. No seu estudo, principalmente voltado aos conglomerados químicos e petrolíferos, Hoffman discute como o mundo empresarial, entre as décadas de 1960 e 1990, passou a incorporar uma série de ações de gestão ambiental na sua estrutura interna. Um dos pontos tratados foi o significativo aumento nos gastos corporativos com ações de proteção e conservação do meio ambiente, como a consolidação de 
departamentos dedicados ao tema, ou, ainda, a expansão no número de empregados que atuariam exclusivamente em atividades de gestão ambiental nas empresas.

Nesse sentido, segundo Hoffman (2001), a institucionalização corporativa da gestão ambiental começa a normalizar atividades, estruturas hierárquicas e profissionais específicos que contemplem a atividade de mercado da empresa junto a requisitos ou temas ambientais. O que configurou uma transformação na perspectiva das empresas em relação às práticas de gestão ambiental as quais deixam de ser interpretadas como uma "ameaça" aos negócios corporativos e passam a ser vistas como "oportunidade"2 -, embora acoplada à dinâmica do mercado e à racionalidade empresarial.

No entanto, pouco se sabe como os atores sociais com responsabilidade na execução das ações ambientais corporativas - os quais circunscrevemos aqui na categoria dos "analistas ou experts ambientais corporativos"3 - articulam, criam e implementam os procedimentos de gestão ambiental empresarial no seu cotidiano.

A exemplo da etnografia de Deborah Bronz (2016) sobre os bastidores das práticas empresariais no licenciamento ambiental, este texto busca analisar algumas práticas cotidianas que determinam o funcionamento do ambientalismo corporativo.

No Brasil, essa análise ganha relevância quando se considera o atual contexto de desmonte das políticas ambientais, em que a liderança das corporações na condução das ações de gestão ambiental no país é acompanhada, paradoxalmente, por uma pressão organizada de seus agentes para flexibilizar e reduzir o rigor do controle da legislação ambiental sobre suas atividades ${ }^{4}$. Um processo que, como

\footnotetext{
"Ameaça" foi o termo utilizado para caracterizar as práticas de gestão ambiental corporativa pela maioria das indústrias que faziam parte do The Conference Board (Conselho Nacional das Indústrias dos Estados Unidos), em 1974 (HOFFMAN, 2001, p. 3).

2 "Oportunidade" foi a designação dada pelo professor de estratégia da Universidade de Harvard, Michael Porter, às ações de proteção e controle ambiental empresarial, em artigo publicado na revista Harvard Business Review, em 1995 (HOFFMAN, 2001, p. 3).

3 Cujo termo aqui se refere ao grupo de especialistas, nas suas distintas especialidades e hierarquias, que integram os departamentos de meio ambiente das grandes corporações, cuja função é conduzir os processos de gestão ambiental corporativos, sejam tais processos vinculados a empreendimentos próprios ou de terceiros, via processos de prestação de serviços ambientais.

${ }_{4}$ Como nos evidenciam Milanez, Magno e Pinto (2019) para o caso das mineradoras no estado de Minas Gerais ou a jornalista Júlia Dolce (2019) para o caso do agronegócio.
} 
destaca Andréa Zhouri, vem reproduzindo um "padrão institucional de produção sistemática da vulnerabilidade" (TONELLI, 2019), evidenciado nos desastres-crimes da mineradora Vale nas bacias dos rios Doce e Paraopeba - os quais contabilizam, além das perdas ambientais, 273 perdas humanas.

Essas catástrofes normalizam, também de forma sistemática, o embate de populações cujos territórios, historicamente conquistados, são continuamente expropriados pelos processos de expansão do capitalismo contemporâneo (HARVEY, 2003 apud RODRÍGUEZ-GARAVITO, 2010, p. 5). O ônus dessas atividades extrativistas acaba pacificado frente às soluções do ambientalismo corporativo, mas os maiores prejuízos da degradação ambiental sempre recaem sobre as populações locais, salientando aqui suas características étnicas, de classe e de raça (ACSELRAD, 2017).

Assim, como poderíamos explicar o aspecto paradoxal que marca a condição histórica do ambientalismo corporativo no Brasil? Nesse mesmo aspecto que faz com que as empresas, ao mesmo tempo, alcancem maior poder decisório sobre suas ações de proteção ambiental, na mesma medida em que sua responsabilidade por tais processos é simplificada ou flexibilizada? Para nós, responder a essa pergunta requer conhecimento de quais usos e sentidos os analistas ambientais mobilizam no curso da prática do ambientalismo corporativo. Isso é, como esses profissionais gerenciam e conceituam as atividades de análise ambiental empresarial no seu cotidiano.

Nosso artigo está divido em três seções. Primeiro, apresentamos o contexto da etnografia, que se dá a partir da experiência pregressa de um dos autores como analista dentro do ambientalismo empresarial, além do detalhamento da metodologia utilizada para a coleta e produção dos dados. Nas segunda e terceira seções, são detalhadas duas situações práticas do ambientalismo corporativo, com o objetivo de descrever e analisar as representações cotidianas que os experts empresariais cultivam no curso da sua atividade, as quais, disseminadas a partir das posições de poder na hierarquia de cargos da análise ambiental corporativa, possuem efeitos substantivos sobre a prática profissional da expertise ambiental empresarial.

$\mathrm{Na}$ conclusão, após o texto destacar a forma como as representações cotidianas do ambientalismo corporativo produzem o distanciamento das 
dimensões de destruição e morte que marcam a instalação de um megaempreendimento, nossa intenção é abrir uma discussão sobre como a antropologia e as ciências sociais podem se consolidar como mediadoras de um "debate sobre valores" (ACSELRAD, 2014, p. 44) no campo traumático da instalação e operação de um megaempreendimento.

\section{O CONTEXTO DA ETNOGRAFIA}

Em setembro de 2010, Rafael da Costa aterrissou na cidade de Altamira, estado do Pará, Região Norte do Brasil, para atuar como "analista ambiental" no processo de instalação da Usina Belo Monte, um projeto de aproveitamento hidrelétrico do rio Xingu, na região conhecida como Volta Grande (Figura 1) ${ }^{5}$. Naquele ano, Costa havia sido contratado pelo departamento de meio ambiente de uma corporação transnacional produtora de energia elétrica que, à época, acabara de ganhar um contrato de prestação de serviços ambientais para o consórcio responsável pela construção da usina ${ }^{6}$.

Nesse pacote de trabalho, as equipes de meio ambiente da corporação foram designadas para executar uma das medidas de compensação e mitigação ambiental da barragem, cujo escopo previa a execução do Plano de Gerenciamento Integrado

\footnotetext{
5 A Volta Grande é a denominação atribuída ao trecho fluvial do rio Xingu com extensão de aproximadamente $140 \mathrm{~km}$ entre a cidade de Altamira-PA e a comunidade de pescadores Belo Monte. O trecho é assim denominado pela acentuada curva que o rio traça na sua área de transição entre o médio e baixo Xingu.

6 Em consonância com os parâmetros éticos para pesquisa em Ciências Humanas previstos na Resolução $n^{\circ}$ 510/2016 do Conselho Nacional de Saúde (CNS), cujo parágrafo único do seu artigo $1^{\circ}$ isenta o registro e avaliação pelo Sistema Comitê de Ética em Pesquisa e Comissão Nacional de Ética em Pesquisa (CEP/CONEP), a "pesquisa que objetiva o aprofundamento teórico de situações que emergem espontânea e contingencialmente na prática profissional, desde que não revelem dados que possam identificar o sujeito" (BRASIL, 2016). A identificação nominal da corporação em que da Costa trabalhou e o consórcio ao qual prestava serviços serão suprimidos. Do mesmo modo, toda e qualquer identificação dos profissionais, tanto do departamento de meio ambiente quanto do consórcio responsável pela construção de Belo Monte, e.g. nome, gênero, idade etc. foi removida. Apenas referências às suas formações acadêmicas e posições na hierarquia dos cargos do ambientalismo corporativo foram mantidas, indispensáveis à análise aqui pretendida.

Com relação à Corporação, para se ter uma ideia do seu campo de atuação num contexto macro, sublinhamos aqui que se trata de uma das maiores organizações produtoras de energia elétrica do mundo, com atuação em mais de cinquenta países. Sua sede mundial está localizada em uma área bastante elitizada de uma das maiores capitais federais da Europa. Na América Latina, seu escritório central está localizado na cidade de Belo Horizonte, Minas Gerais, região Sudeste do Brasil.
} 
da Volta Grande (PGIVG). Um programa cujo objetivo era reunir um conjunto de dados sobre os aspectos físicos, biológicos e socioeconômicos da Volta Grande que poderiam ser "monitorados" e "garantidos" durante e após a instalação da usina. Tal conhecimento era requerido devido à dramática alteração que a instalação da barragem faria no fluxo natural do Xingu, e, consequentemente, nos modos de vida das populações humanas e não humanas que ali habitavam - cuja dinâmica socioambiental era fortemente associada às variações dos ciclos hidrológicos.

\section{Figura 1: Área de influência direta de Belo Monte (e da mineradora Belo Sun, que projeta extrair $\mathbf{7 4}$ toneladas de ouro da Volta Grande).}

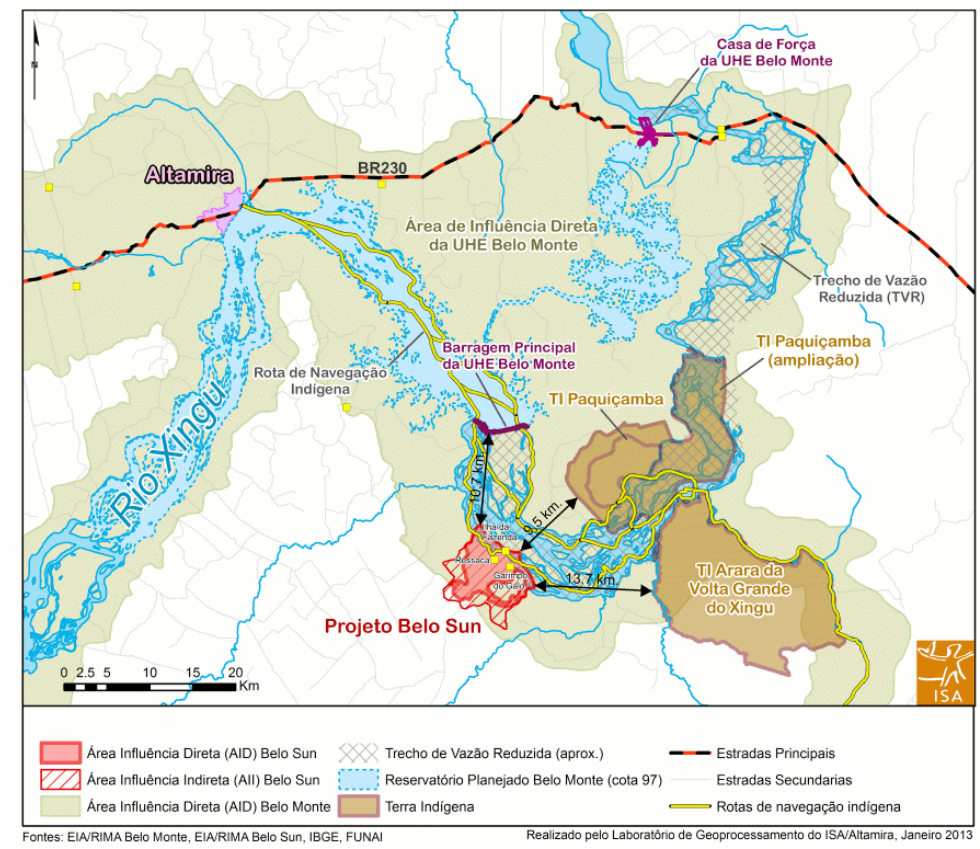

Fonte: Braga e Harari, 2017.

A atuação de Rafael da Costa como analista ambiental do PGIVG esteve concentrada na realização de pesquisas sobre as condições de navegabilidade das populações da Volta Grande do rio Xingu. Afinal, com a instalação da barragem, deveria ser projetada uma alternativa para a manutenção do transporte fluvial entre as regiões a montante e a jusante do barramento, conforme 
determinado pelas condicionantes ambientais do licenciamento da usina (INSTITUTO BRASILEIRO DO MEIO AMBIENTE E DOS RECURSOS RENOVÁVEIS, 2010, 2011). Ademais, com a imposição de uma vazão reduzida no trecho fluvial da Volta Grande a jusante do barramento, eram também necessários a caracterização e o monitoramento da navegação fluvial ali desenvolvida, de modo a subsidiar medidas futuras que garantissem sua manutenção.

Para esse trabalho, Rafael da Costa viveu em Altamira por quase três anos, entre setembro de 2010 a junho de 2013. No período em que conduziu trabalho de campo entre as populações da Volta Grande, produziu relatórios para órgãos ambientais, participou de reuniões públicas nas comunidades, bem como de reuniões internas, restritas aos especialistas do PGIVG e seus clientes (i.e. o consórcio responsável pela instalação da usina), entre outras atividades.

Durante essa experiência, que envolveu "um intenso período de interação" (MOSSE, 2005, p. viii) com outros analistas ambientais corporativos, Costa pôde observar como seus colegas reagiam a determinadas situações de trabalho. O que mais lhe causava estranheza era que tais reações não pressupunham um "caráter ético" ou um "senso de dever", ou, ainda, "a dedicação a uma "causa” comum" (WEBER, 1982, p. 293-294), por parte dos experts ambientais empresariais em relação aos pressupostos legais de suas atividades profissionais, tal como estabelecido pelo imperativo categórico de promover e garantir "um ambiente ecologicamente equilibrado" (BRASIL, [2016]) no contexto da instalação de um megaempreendimento.

Uma vez que as respostas mobilizadas por seus colegas de trabalho em determinadas situações práticas da expertise ambiental empresarial reificavam "atitudes populares", as quais, estabelecidas a partir de "modelos conceituais disponíveis" (HERZFELD, 2016, p. 54) e pelo "balanço corrente do poder" (HERZFELD, 2016, p. 92), não somente dissimulavam as qualidades éticas e o senso de responsabilidade desses profissionais, como, também, funcionavam como "pré-requisitos lógicos" (HERZFELD, 2016, p. 66) para sua tolerância à destruição e à violência implicadas na construção de um megaempreendimento.

Assim, na esteira do antropólogo Michael Herzfeld (2016, p. 54-55), buscamos "examinar criticamente como aqueles que estão no poder [de uma 
instituição tal como o ambientalismo corporativo] usam os símbolos e a retórica existentes para produzir determinismos tão perniciosos".

Nesse sentido, sugerimos aqui nos aproximar dos "códigos internos" (MARCUS, 2010, p. 53) cultivados na intimidade dos experts ambientais corporativos, os quais, independentemente da aparência racional que a expertise empresarial defende publicamente, modificam ou regulam seu funcionamento.

Como apresenta George Marcus (2010, p. 51), as elites tendem a reduzir a "termos humanos" o mundo muito mais vasto do que aquele alcançado por seus modos tecnocráticos de pensamento ${ }^{7}$. Tais termos, constituídos a partir de "entendimentos mais íntimos de relacionamento interpessoal" (MARCUS, 2010, p. 53), e, em contraste com os requerimentos e responsabilidades esperados daqueles que ocupam posições de poder, constituem propriedades capazes de afetar ou regular suas tomadas de decisão (Cf. NADER, 1972).

Assim, a análise que se segue busca problematizar os códigos cultivados pelas elites do ambientalismo corporativo, os quais se estruturam muito além das dimensões objetivas do pensamento das práticas dessa instituição - que, no caso do PGIVG, se expressam por meio dos procedimentos e das especialidades mobilizadas para identificação, avaliação e proposição de medidas reparatórias para os impactos ambientais decorrentes da imposição da vazão reduzida na Volta Grande.

Nesse contexto, nosso objetivo será demonstrar como os usos e sentidos melindrados por tais códigos não podem ser desvinculados dos efeitos de destruição e morte - gerados pela instalação de um megaempreendimento. O que queremos destacar é sua produtividade, ao lado de outros requisitos mais formais da prática corporativa, para garantia e aceitação dos efeitos destrutivos de um megaempreendimento.

\footnotetext{
"Do outro lado da ideologia externa de legitimação das elites [...] gestos e códigos face a face reduzem a complexidade do mundo mais amplo que elas poderosamente afetam a dimensões interpessoais manejáveis. O modo de dominação objetivo, que confortavelmente isola as elites tanto das consequências mais amplas de seus atos, bem como do direto gerenciamento de interesses pessoais, facilita muito essa redução de complexidade. Contudo, até mesmo na mais isolada comunidade de elite [...] um código interno do grupo (in-group code) deve ser formulado frente ao seu envolvimento com um mundo muito mais vasto que aquele alcançado pelas extensões abstratas da sua comunidade, o qual não está totalmente contemplado por seus próprios e limitados modos de compreensão cognitiva" (MARCUS, 2010, p. 52-53; tradução nossa).
} 
Desse modo, o que se verá adiante é a reconstrução de algumas situações sociais da prática do ambientalismo corporativo em Belo Monte, em que tais códigos, sempre atrelados a um modelo cultural pré-existente e definidos a partir de relações de poder, foram registrados. Tal reconstrução foi feita a partir das anotações mais informais do dia a dia da prática do ambientalismo corporativo, reunidas por Rafael da Costa durante sua experiência de trabalho ${ }^{8}$, além de um conjunto de registros (textos, imagens, áudios e documentos técnicos) também reunidos ao longo de sua trajetória como analista ambiental no interior de uma corporação.

\section{“O PROGRESSO VEM AÍ"}

A primeira etapa do trabalho como analista ambiental corporativo de Rafael da Costa, no contexto da execução do PGIVG, consistiu na realização de pesquisas complementares ao Estudo de Impacto Ambiental (EIA) da usina junto aos usuários e ofertantes de serviços de transporte fluvial na região da Volta Grande, especialmente aqueles que navegavam no trecho entre Altamira e as localidades a jusante do barramento principal da hidrelétrica no rio Xingu.

O objetivo da pesquisa era mapear as principais rotas de navegação, registrar seus principais obstáculos, especificar os tipos das embarcações utilizadas, detalhar a finalidade dos deslocamentos, os tipos e quantidade média de cargas transportadas, os custos e tempos das viagens, enfim, compor o que se define nos estudos de monitoramento ambiental como "marco zero" ou "levantamento de referência” da navegação local. Ou melhor, um cenário que pudesse representar a dinâmica dos deslocamentos fluviais na Volta Grande antes de quaisquer intervenções relativas à implantação de Belo Monte.

\footnotetext{
A abordagem metodológica deste trabalho deve muito à obra de Deborah Bronz (2016), que, após atuar por muito tempo em uma empresa de consultoria ambiental no Brasil, em 2011, defendeu sua tese de Doutorado em antropologia sobre as práticas dos profissionais engajados nesse campo. Tal como Bronz, Rafael da Costa possuía uma série de cadernos de campo em que anotava, não somente seus afazeres ordinários, como também as reações de seus colegas durante a rotina de trabalho, as quais, de certo modo, lhe causavam estranhamento (BRONZ, 2013, p. 39-40).

A etnografia de David Mosse (2005) sobre sua experiência como consultor em antropologia em um projeto de desenvolvimento na Índia rural é outra referência decisiva para a nossa pesquisa.
} 
No contexto da realização deste trabalho, é válido destacar que Costa integrava a equipe de campo do PGIVG. Tal equipe, em oposição às equipes do escritório (que gerenciam as atividades de prestação de serviços ambientais desde a sede administrativa da corporação na América Latina - localizada na cidade de Belo Horizonte, região Sudeste do Brasil - onde se encontravam alocados o gerente de meio ambiente e o coordenador de socioeconomia do departamento de meio ambiente empresarial), tem como função a execução, no chão da megaobra, das atividades previstas nos programas de gerenciamento ambiental do empreendimento.

Assim, o contexto da produção de conhecimento para identificação, avaliação e proposição de medidas reparatórias para os impactos ambientais decorrentes da instalação de um megaempreendimento das equipes de campo possui uma dimensão "estética"9 bastante distinta das equipes do escritório. Pois, no campo, a condição de trabalho desses profissionais (i.e. de produção de dados, análises e encaminhamentos ambientais) requer um envolvimento direto, espaço-temporal, com os lugares mais concretos (e sensíveis), objetos das intervenções de um megaempreendimento.

Essa condição de trabalho é apreendida no cotidiano prático das atividades das equipes de campo. No caso da experiência laboral de Rafael da Costa, por exemplo, o mapeamento dos canais de navegação da Volta Grande assinala bem essa dinâmica. Afinal, a definição daquilo que veio a ser conhecido como as "rotas de navegação" utilizadas pelas populações indígenas e não indígenas que habitavam a região só pôde se estabelecer a partir de um "engajamento íntimo" (para utilizar uma expressão de INGOLD, 2014, p. 387) com os barqueiros locais, os únicos portadores capazes de descrever tal conhecimento.

Em outubro de 2011, Costa acompanhou um dos barqueiros responsáveis pelo transporte fluvial das mercadorias que abasteciam os comércios da comunidade da Ressaca, na Volta Grande, bem como de insumos e equipamentos utilizados pelos garimpos existentes naquela localidade (Figura 2).

\footnotetext{
9 No sentido com que o filósofo Jacques Rancière (2009) define a dimensão estética da política. Segundo o autor, "um recorte dos tempos e dos espaços, da visibilidade e da invisibilidade, da palavra e do ruído que definem ao mesmo tempo o lugar e o que está em jogo na política entendida como forma de experiência. A política ocupa-se do que se vêe do que se pode dizer sobre o que é visto, de quem tem competência para ver e qualidade para dizer, das propriedades do espaço e dos possíveis do tempo" (RANCIĖRE, 2009, p. 16-17).
} 
Tal barqueiro realizava essa rota duas vezes por semana. A embarcação utilizada era um barco feito de madeira, com capacidade de carga para até 6 t. E o percurso fluvial possuía aproximadamente $80 \mathrm{~km}$ entre a cidade de Altamira e a Ressaca.

Essa rota, realizada na transição entre o ciclo hidrológico de vazante para enchente do rio Xingu, "quando cai as primeiras águas", segundo um dos barqueiros locais, durava oito horas, considerando-se as três horas de seu percurso de ida, descendo o rio Xingu, até a localidade da Ressaca, e as cinco horas de retorno, subindo o rio, até a cidade de Altamira. Durante todo esse processo, o tempo do analista ambiental é dedicado à escuta atenta dos tripulantes da embarcação (composta por um comandante e dois ajudantes que são também carregadores e proeiros) que narram, vividamente, o conhecimento prático aplicado à navegação pelos canais da Volta Grande.

Figura 2: Mapeamento das rotas fluviais de abastecimento do comércio da
Ressaca e dos garimpos do Galo e do Ouro Verde, na Volta Grande do Xingu.

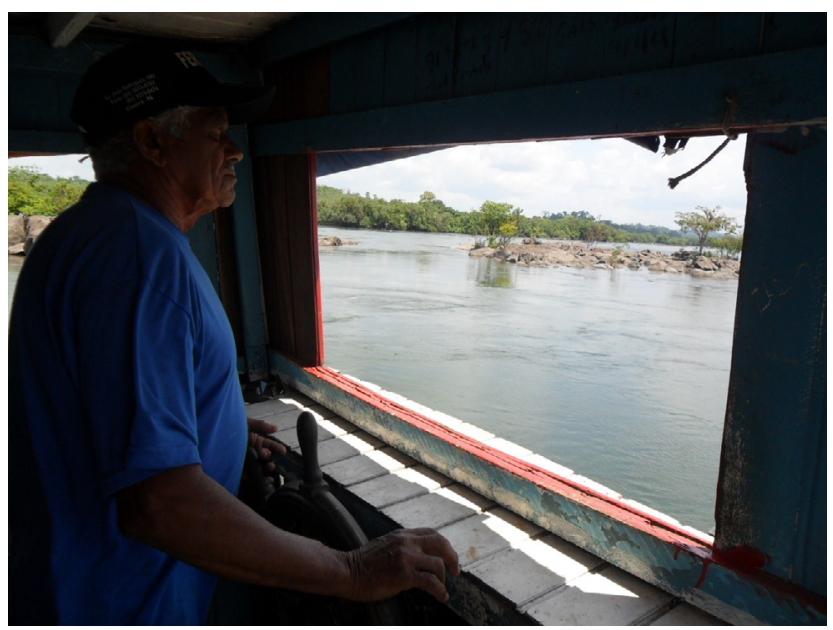

Fonte: Rafael da Costa, 2011.

Isso tudo envolvia um intenso relacionamento interpessoal com as comunidades atingidas por um megaempreendimento. Pois tudo o que se pode ver nos relatórios dos estudos de impacto ambiental e do monitoramento ambiental é como "as condições de vida" (ou as "condições de navegabilidade") dessas populações só podem existir se o analista alcançar uma habilidade mínima de 
percepção de como o conhecimento que essas comunidades detêm é aplicado no decorrer de suas atividades produtivas. Essa constitui uma precondição para a identificação, análise e encaminhamento de questões ambientais no contexto da instalação de um megaempreendimento.

Contudo, do outro lado dessa realidade prática do ambientalismo corporativo, estão as equipes do escritório, mais atarefadas com os processos de prestação de contas das atividades de gestão ambiental empresarial, sejam tais processos estabelecidos com os contratantes de seus serviços (no caso aqui tratado, a concessionária de energia de Belo Monte), assim como para os órgãos ambientais. É o que evidencia um envolvimento por parte dos analistas ambientais corporativos do escritório com uma dinâmica de trabalho massivamente dominada pela produção de documentos escritos. Tudo isso criava demandas muito conflitivas ao quadro do gerenciamento ambiental empresarial. Pois, quando o conhecimento empírico produzido pelas equipes do campo passa a circular na cadeia produtiva do gerenciamento a distância do escritório, a gravidade imanente de seus apontamentos tende a ser banalizada pelas linguagens, emoções e imaginários cristalizados nos ambientes institucionais das sedes administrativas das empresas.

Embora não possamos aqui aprofundar a discussão sobre a divisão do campo sensível (entre o campo e o escritório) da prática do ambientalismo corporativo, esta breve consideração é válida para o argumento que se segue.

Em 14 de abril de 2012, após os primeiros levantamentos sobre as práticas de navegação na Volta Grande, Costa e seus colegas de trabalho de campo foram convidados a apresentar os resultados de suas pesquisas em um Seminário Interno das Equipes de Socioeconomia, realizado pela superintendência do meio socioeconômico da diretoria ambiental do consórcio responsável pela construção da usina. Na ocasião, foram apresentados dados que indicavam a complexa correlação entre os aspectos socioeconômicos das comunidades da Volta Grande e as práticas de navegação, refletida no número variado de rotas fluviais de transporte escolar, escoamento da produção, abastecimento de comércios locais, compra de mantimentos mensais, acesso aos serviços públicos, aos sítios de produção agrícola e de pesca, entre outras. 
Apesar da relativa "simplicidade" das práticas de navegação na Volta Grande, em que a maioria das embarcações era de pequeno porte, calafetadas com madeira e motores de baixa propulsão (Figura 3$)^{10}$, o status material daquela economia atendia perfeitamente às suas demandas ${ }^{11}$. Ademais, entre os pilotos de embarcação com capacidade de carga para até $6 \mathrm{t}$ (o caso dos profissionais que abasteciam o comércio da Ressaca), o conhecimento por eles empreendidos no curso da sua atividade era de se surpreender. Particularmente cientes das características hidrológicas dos canais de navegação locais, esses pilotos tornavam os deslocamentos fluviais possíveis durante todo o ano, mesmo no período de seca do rio Xingu, caracterizado por uma drástica redução de calado.

Contudo, a linguagem usada para classificar todo o universo dos modos de vida das populações atingidas por grandes empreendimentos não está sujeita apenas às definições técnicas e legais que orientam a prática do ambientalismo corporativo para a promoção e garantia de "um ambiente ecologicamente equilibrado" (BRASIL, [2016]) no contexto da instalação de um megaempreendimento, uma vez que modos de entendimento mais íntimos, cultivados tacitamente entre muitos dos profissionais desse campo, podem exceder tal formalismo de maneira a modificar seu funcionamento.

Afinal, após a apresentação das práticas de navegação fluvial naquele seminário, um analista ambiental do alto escalão da superintendência de socioeconomia da concessionária da usina - que na estrutura administrativa de gestão ambiental do consórcio figurava-se no quadro de profissionais do escritório, pois estava alocado na sede da concessionária em Brasília-DF -, teceu o seguinte comentário: "É mesmo surpreendente a forma como a navegação

\footnotetext{
${ }^{10}$ O pequeno porte das embarcações e a baixa propulsão de seus motores era uma característica encontrada entre a grande maioria das embarcações que navegavam a Volta Grande do rio Xingu. Uma pesquisa inicial, realizada entre duzentos residentes da Volta Grande que possuíam embarcações próprias e as utilizavam em deslocamentos fluviais particulares, identificou que mais de $90 \%$ das embarcações registradas eram ou barcos de madeira com capacidade de carga inferior a $1 \mathrm{t}(52,73 \%)$ ou barcos de madeira com capacidade de carga entre 1 até 3 t $(24,61 \%)$ ou canoas $(15,23 \%)$ ou catraias $(0,69 \%)$. Ademais, os motores de baixa propulsão tipo rabeta, com potência máxima de $15 \mathrm{hp}$, eram utilizados por 81,25\% dessas embarcações.

${ }^{11}$ Como, certa vez, a ironia de um morador local fez Rafael da Costa constatar: após ser questionado, durante os seus levantamentos, se existiria algo que, eventualmente, pudesse "melhorar" a situação da navegação local uma pergunta feita na expectativa de registrar questões estruturais passíveis de um eventual aprimoramento, tais como portos, equipamentos e acessórios das embarcações, sinalização fluvial etc. -, esse morador respondeu: "Olha, tendo água e um barco, a gente navega. Mas se secar, só montado num jegue".
} 
na Volta Grande está estruturada, mas não podemos nos esquecer, o progresso vem ai!" (Informal verbal) ${ }^{12}$.

Aquela frase soou como um banho de água fria para Rafael da Costa. Afinal, após mais de um ano de trabalho de campo na Volta Grande que envolveu: 1) a montagem de um extenso banco de dados sobre as práticas de navegação local; 2) mais de 5 mil quilômetros percorridos pelos canais de navegação da Volta Grande para acessar suas comunidades e conhecer a dinâmica dos deslocamentos fluviais; 3) muitas horas de conversa atenta com os pilotos locais que narravam casos de alagamento, dificuldades para traspor fortes corredeiras, enfrentar os banzeiros (ver nota de rodapé 13) ou desviar dos rebojos; e 4) o coração na mão quando acometidos por uma forte chuva num "largo"13.

Figura 3: Barco feito de madeira com capacidade de carga para até 2 t. Embarcação utilizada pelas populações da Volta Grande do rio Xingu.

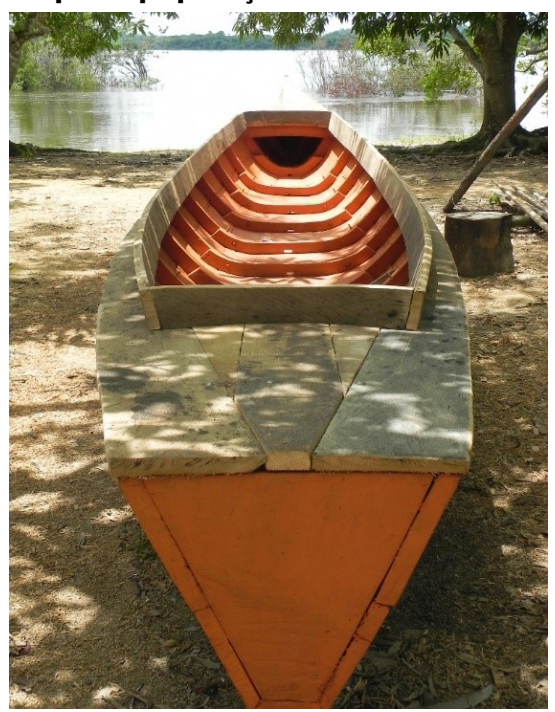

Fonte: Rafael da Costa, 2011.

${ }_{12}$ Informação fornecida por um analista ambiental durante o Seminário Interno das Equipes de Socioeconomia, em Altamira, em 14 de abril de 2012.

13 Os largos do rio Xingu são locais em que a distância entre uma margem e outra do rio é bastante extensa e, por estarem desprotegidos das ilhas e das árvores quando atravessados por fortes rajadas de vento e chuva, formam fortes ondulações, localmente denominadas como "banzeiros", as quais podem exigir a suspensão da navegação e busca por local seguro. Os "banzeiros" configuram um dos principais obstáculos à navegação na Volta Grande, principalmente entre as embarcações de menor porte e com linhas de flutuação menos elevadas, pois, dependendo da força e altura de suas ondas, tais embarcações podem alagar facilmente. 
Tudo para definir um parâmetro confiável - embora nunca estabilizado completamente na linguagem do monitoramento ambiental da usina -, por meio do qual as práticas de navegação pudessem ser monitoradas de modo a "subsidiar propostas, o detalhamento e o acompanhamento da colocação em prática de soluções efetivas para minimizar os impactos negativos [sobre a navegação] já antevistos no EIA", conforme definira um dos objetivos do PGIVG (NORTE ENERGIA, 2011a, p. 425; grifo nosso).

Não obstante, todo o universo prático regular da produção de conhecimento da expertise ambiental corporativa parece ter sua eficácia condicionada à disposição estética de certos profissionais (principalmente aqueles em posições de destaque na hierarquia de comando do ambientalismo corporativo) para conferir usos e sentidos outros que não aqueles definidos por suas especialidades e suas circunstâncias.

Nesse sentido, merece destaque, no registro do cotidiano da prática da análise ambiental corporativa, a descrição de como determinadas interpretações sobre a prática do ambientalismo corporativo subscrevem, de modo eficaz, o estado de morte que demarca os cenários da construção e operação dos megaempreendimentos. A expressão "o progresso vem aí" para se referir às práticas de navegação da Volta Grande não apenas categoriza suas estruturas relativamente simples como "atrasadas", mas, também, as projetam em um futuro no qual já não poderiam mais existir, como, de fato, ocorreu entre muitos de seus praticantes.

O processo de instalação de Belo Monte foi um evento "afundado na rigidez da morte" (para usar uma expressão de BENJAMIN, 1985, p. 50). Durante toda sua construção ${ }^{14}$ foram recorrentes os apontamentos do Ministério Público Federal e da sociedade civil organizada com relação à catástrofe que a usina representava. Entre eles, a denúncia de etnocídio das populações indígenas atingidas (BRASIL, 2015), o processo de expropriação dos modos de vida ribeirinhos (MAGALHÃES; CUNHA, 2017), ou, ainda,

\footnotetext{
${ }_{14}$ A instalação de Belo Monte teve início em setembro de 2011, a partir de emissão da licença de instalação do empreendimento pelo Instituto de Brasileiro do Meio Ambiente e dos Recursos Naturais Renováveis (Ibama). A obra foi concluída em novembro de 2019, com o início da operação da última turbina instalada na casa de forças principal da usina.
} 
o enfrentamento de situações de insegurança alimentar pelas populações Juruna da Volta Grande após a imposição do trecho de vazão reduzida na região (PEZZUTI et al., 2018).

Diante do desastre, nossa reflexão sobre a capacidade daquele funcionário do alto escalão da gestão ambiental de Belo Monte, para caracterizar a navegação nos termos do "progresso", sugere que alguns analistas ambientais empresariais tendem a remover a gravidade e o senso de urgência exigidos da expertise ambiental aplicada a um megaempreendimento. Em seu lugar, proliferam-se "perspectiva[s] assustadoramente desdenhosa[s]" (GOFFEY, 2011, p. xiii), as quais, fundamentadas a partir de "explicações culturalmente convincentes", são capazes de justificar seus "aparentes desvios em relação ao interesse público" (HERZFELD, 2008, p. 25).

Assim, aquilo que o antropólogo Michael Herzfeld (2016, p. 61-62) denomina “a produção social da indiferença” está vivamente expressa nessa relação. Pois, em determinados momentos, parece que a expertise ambiental corporativa não encontra sentido na posição "racionalista” presumida por seus procedimentos tecnocráticos, mas em "fontes simbólicas já disponíveis" capazes de fazer os atores da análise ambiental corporativa se esquivar das suas responsabilidades.

Por esse ângulo, caracterizar as práticas de navegação na Volta Grande nos termos do progresso que, em tese, deveriam estar integradas a um regime de conservação ambiental, não apenas desloca a ênfase em uma postura ética, ou minimamente profissional por parte dos analistas ambientais corporativos, pois revela um universo taxonômico que é também definidor da burocracia empresarial. Tal universo - disponível a partir de retóricas culturais extraídas de uma ordem econômica dominante, e, em estreita correlação ao poder localizado de determinados atores para recorrer a tais retóricas na definição dos usos e sentidos do ambientalismo corporativo -, constitui fator capaz de fazer com que a catástrofe que representa a instalação e operação de um megaempreendimento seja justificada e, consequentemente, legitimada. 


\section{“ESSES CARAS SÃO UNS IDIOTAS"}

Nas pesquisas de monitoramento da navegação na Volta Grande envolviam três grupos de análise, cujos aspectos socioeconômicos e as dinâmicas de deslocamento e acessibilidade deveriam ser acompanhados, a saber: 1) os "usuários" dos serviços de transporte fluvial oferecidos por barqueiros locais; 2) "os donos de embarcação de uso próprio" residentes nas localidades da Volta Grande; e, por fim, 3) os "proprietários de embarcação", prestadores de serviços de transporte fluvial (frete, aluguel, linha etc.).

Durante as pesquisas de monitoramento, foi identificado um segmento dos proprietários de embarcação cuja renda havia diminuído em decorrência da redução da demanda de passageiros após o início das obras da usina. Essa redução ocorreu pelo processo de reassentamento das populações ribeirinhas do rio Xingu, bem como do decréscimo do número de fretes, uma vez que o transporte de cargas para as terras indígenas da região, um serviço usualmente oferecido por esses barqueiros, começara a cair após a aquisição de novos barcos pelos indígenas, uma das medidas de compensação ambiental da usina.

Nesse cenário, o monitoramento dos aspectos socioeconômicos da navegação apontava para a redução da renda desse segmento específico dos proprietários de embarcação ${ }^{15}$. Esse diagnóstico não foi apenas indicado pelas pesquisas de monitoramento, também foi reiterado pelos barqueiros numa reunião pública, realizada em 31 de outubro de 2012, em Altamira, junto aos analistas ambientais responsáveis pelo PGIVG, na qual estavam também presentes os gestores ambientais da concessionária de energia de Belo Monte. Segundo um proprietário de embarcação:

\footnotetext{
15 O grupo dos "proprietários de embarcação" era composto por cinco segmentos ou subgrupos, a saber: o subgrupo 1: proprietários que realizavam fretes de cargas e passageiros em embarcações consideradas de médio porte para a região - barcos de madeira com capacidade de carga entre 3 até $6 \mathrm{t}$ ou superior a $6 \mathrm{t}-$ o qual era composto por dezessete proprietários; o subgrupo 2: proprietários de embarcações que atuavam no transporte fluvial por meio de empresas formalizadas, composto por quatro proprietários; o subgrupo 3: proprietários de embarcações tipo voadeiras que atuavam no transporte fluvial de maneira autônoma, composto por quinze barqueiros; o subgrupo 4: proprietários de embarcações tipo balsas, com capacidade de carga superior a 20 t, prestadores de serviços de frete/aluguel, composto por seis proprietários; e o subgrupo 5: proprietários de embarcações de pequeno porte, barcos de madeira e canoas com capacidade de carga inferior a $3 \mathrm{t}$, prestadores de serviços de frete/aluguel, composto por dezoito barqueiros. A redução da renda entre os "proprietários de embarcação" ocorreu entre os membros dos subgrupos 1 e 3.
} 
A maioria dos moradores das comunidades [ribeirinhas da Volta Grande] já foram remanejados, com isso os pilotos tiveram perdas financeiras em função da diminuição dos fretes na região. Como ficará a situação dos pilotos? (Informação verbal) ${ }^{16}$.

Outro proprietário ainda acrescentou: "Os pilotos perderam também o frete para as aldeias indígenas, pois a concessionária de energia responsável pela construção da hidrelétrica doou voadeiras para as aldeias" (Informação verbal) ${ }^{17}$.

Na ocasião daquela reunião, os barqueiros demandaram uma "compensação financeira para suas perdas”, contudo, a reação dos analistas ambientais corporativos à demanda dos barqueiros foi um tanto inusitada. A proposta feita pelos experts não foi uma definição resolutiva para as perdas registradas, mas a intensificação das atividades de monitoramento para melhor "detalhar as perdas", conforme colocado por um dos profissionais do PGIVG: "Primeiro é necessário um detalhamento desta perda e, em seguida, buscar maneiras de compensar a situação" (Informação verbal) ${ }^{18}$

Essa proposta foi subscrita por um funcionário do alto escalão da concessionária de energia, que reiterou a necessidade de melhor detalhamento da perda "para se chegar à fonte do problema e tentar solucionar" (Informação verbal) ${ }^{19}$. Contudo, a ideia desse monitoramento foi amplamente rechaçada pelos barqueiros, num tipo de "recusa a consentir" (SIMPSON, 2016) com os aparatos tecnocráticos do ambientalismo corporativo. Aquilo que os barqueiros delineavam dizia respeito ao seu próprio projeto político, qual seja a compensação financeira para seus prejuízos e não o que lhes era oferecido pelos experts ambientais empresariais ${ }^{20}$.

\footnotetext{
${ }^{16}$ Informação fornecida por um proprietário de embarcação durante uma reunião pública, em Altamira, realizada em 31 de outubro de 2012.

${ }_{17}$ Informação fornecida por um proprietário de embarcação durante uma reunião pública, em Altamira, realizada em 31 de outubro de 2012.

${ }_{18}$ Informação fornecida por um profissional do PGIGV durante uma reunião pública, em Altamira, realizada em 31 de outubro de 2012.

19 Informação fornecida por um funcionário da concessionária durante uma reunião pública, em Altamira, realizada em 31 de outubro de 2012.

20 Esse argumento deve-se à leitura da antropóloga iroquesa Audra Simpson (2016, p. 327-328) e de seu conceito de "vingança ao consentimento": um conceito utilizado para descrever "as ações deliberadas, desejosas e intencionas que as pessoas fazem diante da expectativa de que elas consentem com a sua própria eliminação enquanto povo, que consentem em ter suas terras tomadas, suas vidas controladas, e suas histórias contadas por eles".
} 
No entanto, os analistas ambientais presentes naquela reunião não só defenderam a ideia da intensificação das atividades de monitoramento (como se os resultados já não fossem suficientes para registrar a perda econômica dos barqueiros), como sugeriram inserir a Cooperativa de Barqueiros de Altamira (que reunia muitos dos presentes naquela reunião) no "cadastro de fornecedores da concessionária de energia”. A justificativa era "criar novas possibilidades de contratação para aqueles profissionais", bem como "oportunidades de geração de renda” para os barqueiros no novo cenário socioeconômico da região pós-instalação da usina.

Novamente, essa proposta foi rechaçada pelos barqueiros com o argumento que a "inclusão da cooperativa no cadastro de fornecedores" era uma forma de dissimular a indenização pelas perdas anteriores: "Essa oportunidade de inserir a cooperativa no cadastro de fornecedores e utilizar os serviços da cooperativa é para descartar a indenização pelas perdas anteriores?” (Informação verbal) ${ }^{21}$.

Mas as tentativas dos experts ambientais corporativos de ditar os modos que consideravam ser os mais adequados para a recomposição das perdas econômicas dos barqueiros não cessavam. Numa reunião posterior, realizada em 22 de novembro de 2012, uma nova estratégia foi apresentada. Agora, o que era oferecido, ao lado do monitoramento dos aspectos socioeconômicos dos barqueiros e do "cadastro dos barqueiros à rede de fornecedores da concessionária", era a realização de uma "pesquisa sobre o perfil dos profissionais fluviais" (Informação verbal) ${ }^{22}$.

Tal pesquisa seria realizada pelas equipes de uma empresa de consultoria ambiental responsável pelo Programa de Recuperação das Atividades de Turismo e Lazer (PRATL), mais uma medida compensatória da usina, cujo objetivo era "potencializar as oportunidades criadas pelo empreendimento" na região (NORTE ENERGIA, 2011b, p. 410) Segundo os técnicos do programa, tais “oportunidades" decorreriam da articulação entre os setores públicos e privados para a promoção do turismo, da implementação de obras voltadas

\footnotetext{
${ }^{21}$ Informação fornecida por um barqueiro durante uma reunião pública, em Altamira, realizada em 31 de outubro de 2012.

22 Informação fornecida por um funcionário da concessionária, em reunião aberta, em Altamira, em 22 de novembro de 2012.
} 
para a recuperação das atividades de lazer e do aumento da demanda de turistas após o enchimento do reservatório.

Desse modo, segundo os analistas do PRATL, "os profissionais da área de transporte fluvial" seriam, todos eles, beneficiados pelas atividades do programa, que representavam "um espaço de grandes oportunidades" para os proprietários de embarcação (Informação verbal) ${ }^{23}$.

No entanto, outra vez, a proposta soou como algo muito distante para os barqueiros. Um deles questionou "quando o turismo iria chegar", afirmando que, até que isso acontecesse, "os pilotos já estariam passando fome, porque estão perdendo sua renda” (Informação verbal) ${ }^{24}$. Outro piloto, que operava a embarcação de madeira ilustrada na Figura 2, não hesitou em avaliar a chegada do turismo como algo positivo, mas enfatizou que "nem todos estão preparados para trabalhar nessa área", pois, "muitos proprietários não têm barcos novos e/ou adequados para esse tipo de transporte" (Informação verbal) ${ }^{25}$. Outros ainda questionaram, ironicamente, que, se o reservatório da Usina de Belo Monte inundaria todas as praias da região ${ }^{26}$, "quais turistas iriam transportar?" (Informação verbal) ${ }^{27}$.

Contudo, os experts do PRATL insistiam no seu argumento, e assim se desenhava a prática oficial do ambientalismo corporativo em Belo Monte, num movimento que desestabilizava a perspectiva dos barqueiros locais sobre a reparação dos danos causados pelo megaempreendimento, a partir da imposição da perspectiva exclusiva dos experts sobre o que seria essa reparação.

Assim, é preciso admitir e questionar tamanho descompasso entre os posicionamentos, de um lado os experts corporativos, e, de outro, as

\footnotetext{
${ }^{23}$ Informação fornecida por um analista do PRATL, em reunião aberta, em Altamira, em 22 de novembro de 2012 .

${ }^{24}$ Informação fornecida por um barqueiro, em reunião aberta, em Altamira, em 22 de novembro de 2012.

25 Informação fornecida por um barqueiro, em reunião aberta, em Altamira, em 22 de novembro de 2012.

${ }^{26}$ O rio Xingu é caracterizado por uma variação significativa do volume de água escoado entre os períodos chuvosos e de estiagem, localmente denominados enquanto as estações de "inverno" e "verão", respectivamente. Tal sazonalidade do regime pluvial, pelas características hidrológicas do Xingu, fazia emergir, no período de estiagem, belas praias fluviais. Essas praias configuravam o principal destino para as atividades de lazer e recreação não só dos altamirenses, mas também de turistas que buscavam a cidade nas temporadas veraneias. Com a instalação de Belo Monte, e a conformação de seu reservatório principal no leito do rio Xingu, grande parte das praias fluviais afloradas no período de estiagem ficariam constantemente submersas, reduzindo dramaticamente as opções de lazer na região.

27 Informação fornecida por um barqueiro, em reunião aberta, em Altamira, em 22 de novembro de 2012.
} 
comunidades atingidas, cujo efeito é o adiamento interminável das medidas de reparação de danos urgentes e imediatas requeridas no contexto de um megaempreendimento. Afinal, no caso dos barqueiros, se todo o quadro das perdas socioeconômicas dessa classe já havia sido previamente sinalizado pelas pesquisas de monitoramento da navegação, qual seria a razão para que essa realidade não fosse percebida, na urgência da sua constatação, pelos experts ambientais corporativos presentes naquele evento?

Os registros das perdas econômicas do grupo de barqueiros da Volta Grande foram coletados entre outubro e novembro de 2012. Em junho de 2016, como pesquisador independente em Altamira, Rafael da Costa teve a oportunidade de conversar com um dos barqueiros presentes nas duas reuniões de 2012 (o mesmo com quem realizara o mapeamento das rotas de abastecimento do comércio e do garimpo da Ressaca), e que informou já não mais ofertar serviços de transporte fluvial na região: "Não há mais passageiros nem cargas para transportar" (Informação verbal) ${ }^{28}$.

Em 2016, o proprietário utilizava seu barco para extrair areia do rio Xingu, uma ocupação que não gerava os mesmos rendimentos do transporte fluvial. Ele nunca fora ressarcido pela perda de sua atividade econômica original e jamais recebera qualquer assistência técnica durante a mudança de ocupação. Esse barqueiro culpava a Barragem Belo Monte pela sua condição atual, bem como a empresa Belo Sun, uma corporação minerária canadense que expropriou dezenas de famílias da comunidade garimpeira da Ressaca, na Volta Grande, para dar lugar a uma mina de ouro, o que também reduziu a demanda por transporte de carga e passageiros.

Em 2012, quando Rafael da Costa apresentou, pela primeira vez, as evidências das perdas econômicas do segmento específico de barqueiros para um de seus superiores (que estava alocado na sede administrativa da empresa, em Belo Horizonte), ele também apresentava outra lista de barqueiros - donos de empresas formais prestadoras de serviços de transporte fluvial na região ${ }^{29}-$,

\footnotetext{
28 Informação fornecida por um barqueiro, em entrevista, em Altamira, em 26 de junho de 2016.

29 Integrantes do subgrupo 2 do público alvo das pesquisas de monitoramento da navegação, ver nota de rodapé 14 .
} 
os quais estavam, efetivamente, capitalizando suas atividades após o início das obras de Belo Monte. Uma vez que seus rendimentos estavam aumentando, suas frotas estavam expandindo, bem como sua oferta de serviços se diversificava. Tudo isso ocorrera em função da demanda crescente de empresas responsáveis pela construção da usina por serviços de transporte fluvial.

Após comparar os dois diagnósticos, seu superior, referindo-se aos barqueiros com perdas econômicas, exclamou, em tom meio irritado, embora também descontente e desapontado: “Esses caras são uns idiotas!".

Novamente, com o mesmo espanto após ouvir a frase "o progresso vem aí", Costa ficou paralisado, pois, definitivamente, não esperava aquela reação. E, na sequência daquela interpretação descomedida em relação à situação dos barqueiros, qualquer embasamento técnico sobre a redução dos rendimentos daquele grupo seleto de barqueiros lhe parecia impossível. Embora tenha sido essa sua atitude, a habilidade para debater "se os barqueiros eram idiotas ou não" representava a competência para dialogar valores e sentimentos que, pela sua casualidade ou pelo seu imprevisto, configurava tarefa bastante improvável.

Ora, tratar os barqueiros como idiotas não é uma habilidade que se espera de uma analista ambiental empresarial, nem responder a esse tipo de tratativa, pois essas são reações que mobilizam domínios não-técnicos ou não-discursivos. Ou seja, essas reações, bem como qualquer resposta que se possa ter a elas, não estão disponíveis a partir das normas e das técnicas da expertise ambiental corporativa, mas a partir de relações de poder. Por outro lado, elas não estão disponíveis a partir do ponto de vista científico em relação ao licenciamento ambiental de uma megaobra, mas do ponto de vista do imaginário, dos afetos e da racionalidade neoliberal baseada no empreendedorismo mobilizado pelos distintos profissionais da análise ambiental corporativa ${ }^{30}$.

Como demonstrou Deborah Bronz (2019), quando determinados termos técnicos de gerenciamento ambiental empresarial, como o termo "comunidade",

\footnotetext{
30 A leitura de Deleuze (2012) e sua discussão sobre a sociedade de controle expressa no estudo da racionalidade neoliberal, nos ajuda na definição deste argumento. Como aponta Oliveira (2016, p. 17) sobre isso: "[Segundo Deleuze], o investimento em capital humano requer uma alma empresa em que o empreendedorismo de si será o elemento que irá inserir um conjunto de ações, condutas e comprometimentos com esta alma dos controles contínuos". No caso da expertise ambiental corporativa, ela não apenas reproduz esta conduta empreendedora como também se espera promovê-la para compensação de populações atingidas.
} 
eles assumem valores afetivos e simbólicos que escapam à moral e à ideologia mercadológica que domina as instituições do ambientalismo corporativo, as quais tendem a orientar as ações de reparação dos danos provocados por um megaempreendimento a partir de investimentos em planos de desenvolvimento econômico, esses valores outros são frequentemente rechaçados com perplexidade, indagação, discordância e murros na mesa ${ }^{31}$.

É nesse sentido que essas reações, sempre atreladas ao "poder localizado no acesso imediato a um recurso assaz trivial" (HERZFELD, 2016, p. 152), capaz de justificar os desvios com relação ao interesse público, bem como eximir as responsabilidades implicadas na expertise ambiental empresarial, tornam-se formas de expressão cujo diálogo (técnico) é difícil de estabelecer. Afinal, quem pode definir os barqueiros como idiotas ou caracterizar a navegação nos termos do progresso no interior de uma corporação? No entanto, mais além das relações de poder, nenhuma das especialidades que adentram o mundo da expertise ambiental corporativa é capaz de reagir (racionalmente) a expressões tão distantes dos sentidos práticos (técnicos, éticos e legais) dessa atividade no contexto de uma megaobra. Essa é uma tarefa para a antropologia e para as ciências sociais.

Por exemplo, as dimensões daquilo que Parry Scott (2012, p. 138) denomina "descaso planejado", isso é, a negação das reparações ou dos benefícios aos quais determinados grupos da sociedade teriam pleno direito, estão também circunscritas em relações definidas por aspectos não-técnicos da prática da análise ambiental. O próprio Scott (2012, p. 137-138) desenvolve esta tese quando elenca, entre as dimensões do desmonte das políticas ambientais, a "desmoralização" das populações atingidas. Após uma experiência profissional no campo do ambientalismo corporativo, Scott (2012, p. 137) pôde registrar como as populações atingidas são tratadas na intimidade destas instituições,

\footnotetext{
${ }^{31}$ No seu texto, Bronz (2019, p. 336-337) detalha a reação enrubescida do vice-presidente de uma empresa em uma discussão sobre as medidas compensatórias de algumas comunidades de pescadores afetadas por um empreendimento portuário. De forma indiferente, este vice-presidente se recusa a comprar o terreno para construir um pequeno estaleiro para os pescadores, em local já familiar aos encontros e atividades da categoria, por ser muito caro, sugerindo que o estaleiro deveria ser construído em outro lugar, em que o preço do terreno seria menor. No entanto, quando o vice-presidente foi contrariado pelo argumento de que o local indicado para a construção do estaleiro possuía "grande 'valor simbólico' para as comunidades", ele "num tom de perplexidade, indagação e discordância, bateu com a mão fechada na mesa... e indagou: 'Valor simbólico???”.
} 
em ambientes em que o que prolifera são representações sobre os atingidos pela sua "esperteza", ao demandarem benefícios dos programas ambientais corporativos, e não como sujeitos portadores de direito.

É nesse contexto que os antropólogos devem se aproximar daquilo que é dito no cotidiano das práticas do ambientalismo corporativo, pois suas propriedades incluem "características taxonômicas" (HERZFELD, 2016, p. 50) que devem ser mensuradas, uma vez que também fazem essa instituição funcionar e prosseguir com seus desastres. Pois os dizeres cotidianos ou mais casuais daqueles que estão em posição de poder para dizê-los e praticá-los, nos bastidores do ambientalismo corporativo, constituem artifícios poderosos para manejar, a distância, as dimensões de violência e de morte que atravessam as populações atingidas por um megaempreendimento.

Este ensaio é um convite para que antropólogos e outros cientistas sociais se aproximem, analítica e politicamente, da reprodução de tais artifícios na instituição do ambientalismo corporativo, bem como em outras instituições de poder.

\section{PARA DISCUSSÃO: O FAZER ANTROPOLÓGICO NO CAMPO DOS CONFLITOS AMBIENTAIS}

Este texto buscou se aproximar de algumas situações cotidianas da prática da expertise ambiental corporativa, observadas em duas circunstâncias práticas de trabalho de um dos autores no departamento de meio ambiente de uma corporação. Nessa abordagem, podemos perceber que, em determinadas posições de poder localizadas, os analistas ambientais empresarias fazem uso de certas convenções sociais há muito estabelecidas para dissimular os sensos de dever e responsabilidade esperados do ambientalismo corporativo, bem como estabelecer as condições de aceitabilidade das dimensões destrutivas e de morte do capitalismo.

Essa constatação reforça o posicionamento da antropologia e das ciências sociais nesse campo de batalha, a fim de se consolidarem como instrumentos mediadores de um "debate sobre valores" (ACSELRAD, 2014, p. 44) no ambiente traumático da instalação e operação de um megaempreendimento, de modo a 
abrir espaço para que os idiomas "não-técnicos" ou "não-oficiais", mobilizados na intimidade das instituições do ambientalismo corporativo, sejam problematizados publicamente.

Afinal, imaginamos cada vez mais antropólogos e sociólogos realizando trabalhos de campo de longo prazo nas instituições do ambientalismo corporativo (entre outras instituições poderosas das sociedades capitalistas) e devolvendo aos interlocutores desse campo os interesses culturalmente determinados que informam sua prática.

Se os pressupostos legais da política do licenciamento ambiental terminam como um "jogo de cena de procedimentos democráticos" (ZHOURI, 2008, p. 101) ou "mero instrumento viabilizador" da exploração econômica do meio ambiente como recurso material, esses mesmos pressupostos, nos idos de sua concepção, previam a abertura de um amplo "debate sobre a viabilidade dos empreendimentos", bem como a colocação em prática de um "instrumento de avaliação da sustentabilidade socioambiental das obras" (ZHOURI, 2008, p. 103). Isso porque, no cotidiano das instituições responsáveis por tais políticas, valores cultivados a partir de posições poderosas, e altamente contraditórios ao que essas instituições historicamente inauguraram, são reiterados incessantemente.

Acercar-se da reprodução de valores no dia a dia da prática da expertise ambiental corporativa é uma forma de refletir e questionar o funcionamento e a continuidade das políticas ambientais. Colocar-se nesse campo de luta, e não calar o debate aberto, é condição do trabalho do cientista social.

\section{REFERÊNCIAS BIBLIOGRÁFICAS}

1. ACSELRAD, Henri. A crítica do "ambiente" e o ambiente da crítica. Antropolítica, Niterói, n. 36, p. 27-47, 2014.

2. ACSELRAD, Henri. Mariana, November, 2015: the political genealogy of a disaster. Vibrant, Brasília, DF, v. 14, n. 2, p. 1-10, 2017.

3. BENJAMIN, Walter. Central Park. New German Critic, Ithaca, n. 34, p. 32-58, 1985. 
4. BRAGA, Oswaldo; HARARI, Isabel. Avança destruição do Rio Xingu. Instituto Socioambiental (ISA), Altamira, 3 fev. 2017. Disponível em: https://bit.ly/39qgieT. Acesso em: 4 jul. 2020.

5. BRASIL. [Constituição (1988)]. Constituição da República Federativa do Brasil de 1988. Brasília, DF: Presidência da República, [2016]. Disponível em: https://bit.ly/3fWdlVS. Acesso em: 4 jul. 2020.

6. BRASIL. Ministério Público Federal. Ação Civil Pública com pedido de liminar. Altamira: Procuradoria da República de Altamira, 2015. Disponível em: https://bit.ly/39llxwr. Acesso em: 22 jul. 2020.

7. BRASIL. Resolução n 510, de 7 de abril de 2016. O Plenário do Conselho Nacional de Saúde em sua Quinquagésima Nona Reunião Extraordinária [...] no uso de suas competências regimentais e atribuições conferidas pela Lei no 8.080, de 19 de setembro de 1990, pela Lei no 8.142 , de 28 de dezembro de 1990, pelo Decreto ${ }^{\circ} 5.839$, de 11 de julho de 2006. Brasília, DF: Ministério da Saúde, 2016. Disponível em: https://bit.ly/3eRzgvZ. Acesso em: 22 jul. 2020.

8. BRONZ, Deborah. "O Estado não sou eu”: Estratégias empresariais no licenciamento ambiental de grandes empreendimentos industriais. Campos, Curitiba, v. 14, n. 1/2, p. 37-55, 2013.

9. BRONZ, Deborah. Nos bastidores do licenciamento ambiental: uma etnografia das práticas empresariais em grandes empreendimentos. Rio de Janeiro: Contracapa, 2016.

10. BRONZ, Deborah. As comunidades não cabem nos modelos: análise de um manual empresarial de relacionamento com comunidade. In: TEIXEIRA, Carla Costa; LOBO, Andréa; ABREU, Luiz Eduardo (org.). Etnografia das instituições, práticas de poder e dinâmicas estatais. Brasília, DF: ABA, 2019. p. 311-340.

11. DELEUZE, Gilles. Conversações. Tradução: Peter Pal Pelbart. São Paulo: Editora 34, 2012.

12. DOLCE, Júlia. Como ruralistas transformaram o projeto de licenciamento ambiental em ataque à fiscalização. De Olho nos Ruralistas, São Paulo, 6 fev. 2019, 11:53. Disponível em: https://bit.ly/3fTe0XZ. Acesso em: 5 jun. 2020.

13. GOFFEY, Andrew. Introduction: on the witch's broomstick. In: PIGNARRE, Philippe; STENGERS, Isabelle. Capitalist sorcery: breaking the spell. Londres: Palgrave Macmillan Stengers, 2011. p. viii-xxiv.

14. HERZFELD, Michael. Intimidade Cultural: poética sociais no Estado-Nação. Lisboa: Edições 70, 2008.

15. HERZFELD, Michael. A produção social da indiferença: explorando as raízes simbólicas da burocracia ocidental. Petrópolis: Vozes, 2016. 
16. HOFFMAN, Andrew. From heresy to dogma: an institutional history of corporate environmentalism. Stanford: Stanford University Press, 2001.

17. INGOLD, Tim. That's enouth about ethnography. Hau, Londres, v. 4, n. 1, p. 383-395, 2014.

18. INSTITUTO BRASILEIRO DO MEIO AMBIENTE E DOS RECURSOS RENOVÁVEIS. Licença prévia de Belo Monte. Brasília, DF: Ministério do Meio Ambiente, 2010.

19. INSTITUTO BRASILEIRO DO MEIO AMBIENTE E DOS RECURSOS RENOVÁVEIS. Licença de instalação de Belo Monte. Brasília, DF: Ministério do Meio Ambiente, 2011.

20. MAGALHÃES, Sônia Barbosa; CUNHA, Manuela Carneiro da. A expulsão de ribeirinhos em Belo Monte: relatório da SBPC. São Paulo: SBPC, 2017.

21. MARCUS, George. Elite Communities and Institutional Orders. In: MARCUS, George (ed.). Elites: ethonographical issues. 2. ed. London: Routledge, 2010, p. 41-57.

22. MILANEZ, Bruno; MAGNO, Lucas; PINTO, Raquel Giffoni. Da política fraca à política privada: o papel do setor mineral nas mudanças da política ambiental em Minas Gerais, Brasil. Cadernos de Saúde Pública, Rio de Janeiro, v. 35, n. 3 , p. 1-7, 2019.

23. MOSSE, David. Cultivating Development: an ethnography of aid policy and practice. Londres: Pluto Press, 2005.

24. NADER, Laura. Up the Anthropologist: perspectives gained from studying up. In: Hyme, Dell (ed.). Reinventing Anthropology. New York: Random House, 1972. p. 284-331.

25. NORTE ENERGIA. Projeto básico ambiental da Usina Hidrelétrica Belo Monte. Brasília, DF: CENEC Worley Parsons; Leme Engenharia, 2011a. v. VI.

26. NORTE ENERGIA. Projeto Básico Ambiental da Usina Hidrelétrica Belo Monte. Volume II. Brasília, DF: CENEC Worley Parsons; Leme Engenharia, 2011b. v. II.

27. OLIVEIRA, Maria Cecilia. Os objetivos de desenvolvimento do milênio: a vida segura na governamentalidade libertária. 2016. Tese (Doutorado em Ciências Sociais - Pontifícia Universidade Católica de São Paulo, São Paulo, 2016.

28. PEZZUTI, Juarez; CARNEIRO, Cristiane; MANTOVANELLI, Thais; GARZÓN, Biviany Rojas. Xingu, o rio que pulsa em nós: monitoramento independente para registro de impactos da UHE Belo Monte no território e no modo de vida do povo Juruna (Yudjá) da Volta Grande do Xingu. São Paulo: ISA, 2018. 
29. RANCIÈRE, Jacques. A partilha do sensível: estética e política. Tradução Mônica Costa Netto. São Paulo: EXO experimental; Editora 34, 2009.

30. RODRÍGUEZ-GARAVITO, César. Ethnicity.gov: global governance, indigenous peoples, and the right to prior consultation in social minefields. Indiana Journal of Global Legal Studies, Bloomington, v. 18, n. 1, p. 1-44, 2010.

31. SCOTT, Parry. Descaso planejado: uma interpretação de projetos de barragem a partir da experiência da UHE Itaparica no rio São Francisco. In: ZHOURI, Andréa (org.). Desenvolvimento, reconhecimento de direitos e conflitos territoriais. Brasília, DF: ABA, 2012. p. 122-146.

32. SIMPSON, Audra. Consent's Revenge. Cultural Anthropology, Arlington, v. 31, issue 3, p. 326-333, 2016.

33. TONELLI, Luciana. A ideologia da Mineração está em xeque. Outras Palavras, São Paulo, 13 set. 2019, 14:46. Disponível em: https://bit.ly/3eVtp8R. Acesso em: 17 out. 2019.

34. WEBER, Max. Ensaios de sociologia. 5. ed. Rio de Janeiro: LTC, 1982.

35. ZHOURI, Andréa. Justiça ambiental, diversidade cultural e accountability: desafios para a governança ambiental. Revista Brasileira de Ciências Sociais, São Paulo, v. 23, n. 68 , p. $97-107,2008$. 